\title{
Cidadania deliberativa e gestão social: revisão sistemática de literatura no Brasil
}

RAFAel Junior dos SANTOS Figueiredo SALGado ${ }^{1}$

LUANA FERREIRA DOS SANTOS ${ }^{1}$

TAMIRIS CRISTHINA RESENDE ${ }^{1}$

WASHINGTON JOSÉ DE SOUZA ${ }^{1}$

${ }^{1}$ Universidade Federal do Rio Grande do Norte (UFRN) / Programa de Pós-Graduação em Administração, Natal - RN, Brasil

\begin{abstract}
Resumo
Esta revisão sistemática de literatura de cidadania deliberativa e gestão Social tem por objetivo analisar o modo como o conceito habermasiano de cidadania deliberativa é aplicado em estudos de gestão social no Brasil. Para tanto, foram consultadas as bases de dados Periódicos Capes e Google Acadêmico, usando os descritores "cidadania deliberativa" e "gestão social". A maioria dos artigos foi publicada em revistas classificadas no estrato Qualis Capes A2, tendo como principal periódico o Cadernos EBAPE.BR. A análise das estratégias metodológicas empregadas revela opções qualitativas, com 7 trabalhos caracterizados como ensaios teóricos e 11 estudos teóricos-empíricos, predominando a aplicação da concepção de cidadania deliberativa em territórios rurais e conselhos. Os resultados teórico-empíricos enfocam desafios e oportunidades de pesquisa e (re)afirmam que o processo de cidadania deliberativa habermasiano pode ser tomado como estratégia de gestão social. De outra forma, os textos teóricos indicam que o constructo cidadania deliberativa constitui base relevante para a construção do domínio da gestão social.
\end{abstract}

Palavras-chave: Cidadania deliberativa. Jürgen Habermas. Gestão social. Participação social.

\section{Deliberative citizenship and social management: a systematic literature review in Brazil}

\begin{abstract}
This systematic literature review about deliberative citizenship aims to synthesize, in social management studies in Brazil, the application of the concept as portrayed by Habermas. The Periódicos Capes and Academic Google databases were searched using the descriptors "deliberative citizenship" and "social management." Most of the articles were published in journals classified in the stratum Qualis Capes A2, and in Cadernos EBAPE.BR. The analysis of the methodological strategies employed reveals qualitative options, with seven papers characterized as theoretical essays and eleven papers as theoretical-empirical, by the application of the concept of deliberative citizenship in territories and councils. The theoretical-empirical results focus on challenges and opportunities and indicate that the process of Habermasian deliberative citizenship can constitute a social management strategy. The theoretical texts indicate that the construct deliberative citizenship provides elements related to the construction of the domain of social management.
\end{abstract}

Keywords: Deliberative citizenship. Jürgen Habermas. Social management. Social participation.

\section{Ciudadanía deliberativa y gestión social: una revisión sistemática de la literatura en Brasil}

\section{Resumen}

Esta revisión sistemática de la literatura sobre ciudadanía deliberativa y gestión social tiene como objetivo analizar la aplicación del concepto habermasiano de ciudadanía deliberativa en estudios de gestión social en Brasil. Para ello, se consultaron las bases de datos Periódicos Capes y Google Académico con los descriptores "ciudadanía deliberativa" y "gestión social". La mayoría de los artículos fue publicada en periódicos de categoría Qualis Capes A2, entre los cuales el principal es Cadernos EBAPE.BR. El análisis de las estrategias metodológicas empleadas revela opciones cualitativas, con 7 trabajos caracterizados como ensayo teórico y 11 trabajos teórico-empíricos, en los cuales predomina la aplicación de la concepción de ciudadanía deliberativa en territorios rurales y concejos. Los resultados teórico-empíricos enfocan desafíos y oportunidades de investigación y reafirman que el proceso de ciudadanía deliberativa habermasiana puede emplearse como estrategia de gestión social. Por otro lado, los textos teóricos indican que el constructo ciudadanía deliberativa es una base relevante para la construcción del dominio de la gestión social.

Palabras clave: Ciudadanía deliberativa. Habermas. Gestión social. Participación social. 


\section{INTRODUÇÃO}

Esta revisão sistemática de literatura tem objetivo analisar o modo como o conceito de cidadania deliberativa, proposto por Jürgen Habermas, é aplicado em estudos de gestão social no Brasil. Tal conceito está vinculado à concepção de uma razão comunicativa, propondo o autor uma mudança de paradigma para substituir a filosofia da consciência, de Max Horkheimer e Theodor Adorno, por uma teoria da intersubjetividade comunicativa (FREITAG, 1994). E Freitag (1994) defende que a relevância da atuação conjunta dos teóricos da Escola de Frankfurt recai sobre a capacidade intelectual e crítica, a reflexão dialética e a competência dialógica. A autora destaca que a base da teoria crítica é a emancipação, conectada à substituição de uma racionalidade instrumental por uma razão emancipatória do homem, configurada pelo conceito de racionalidade comunicativa, por uma reflexão radical coletiva, democrática, e por uma renegociação política entendida como o domínio em que todos devem participar.

Apesar de Habermas concordar com a crítica de Hockheimer e Adorno à razão instrumental, dificultando a autonomia social dos indivíduos, ele concebe uma saída para o homem sem deixar de lado o progresso técnico-científico (TENÓRIO, 1998). Para tanto, formula um paradigma teórico-social para fazer frente a esse tipo de razão instrumental, cujo consenso deve ser alcançado por uma ação social do tipo comunicativa. A racionalidade comunicativa de Habermas (2011a) se refere, portanto, às relações em que, mediante ação comunicativa, os interessados se envolvem com o mundo quando reivindicam validade para suas manifestações ou emissões. Essa racionalidade está voltada à descentralização da compreensão de mundo, que é uma das condições necessárias para uma sociedade emancipada.

No Brasil, foi Tenório (1998) quem originalmente incorporou a discussão habermasiana de cidadania deliberativa à gestão social. A discussão integrada dos dois construtos está centrada na participação, uma vez que a "gestão social deve ser praticada como processo intersubjetivo, dialógico, no qual todos têm direito à fala" (TENÓRIO, 2005, p. 121). A autodeterminação, segundo Tenório (1998), não se dá sob a lógica do mercado, mas sim da democracia social pela via da igualdade política e decisória. É este, pois, o antecedente que justifica a revisão sistemática aqui apresentada. Em momentos posteriores, vários autores brasileiros incorporaram o conceito de cidadania deliberativa à gestão social e, assim, o exercício desta revisão está direcionado a revelar o modo como tais usos ocorreram a partir da seguinte questão:

- De que modo se apresentam, no domínio da gestão social, preceitos habermasianos de cidadania deliberativa e qual é o perfil da produção acadêmica no tocante à autoria no Brasil?

A revisão parte da premissa de que o exercício da cidadania deliberativa requer participação, todavia, contrapondo-se à concepção de cidadão em perspectiva liberal, considerando que o fundamento desta reside em direitos subjetivos que se aperfeiçoam diante do Estado e dos demais cidadãos, dentro de limites estabelecidos por leis, em proveito particular, privado (HABERMAS, 1995).

Os trabalhos que analisam as aproximações teórico-conceituais das teorias de Jürgen Habermas com a gestão social se pautam na esfera pública (OLIVEIRA, CANÇADO e PEREIRA, 2010; GARCIA, 2016; PERSSON, 2016) ou apropriam-se dos conceitos habermasianos para analisar ações e experiências alicerçadas na gestão social (ALLEBRANDT, SIEDENBERG, SAUSEN et al., 2011; IIZUKA, GONÇALVES-DIAS e AGUERRE, 2011, 2012; ALLEBRANDT, BENSO e OLIVEIRA, 2015). Assim, a discussão aqui traçada inova não apenas ao realizar o exercício teórico-empírico de aproximação entre gestão social e a concepção habermasiana de cidadania deliberativa, mas também ao revelar o modo como os dois constructos se encontram abordados, conjuntamente, na produção intelectual brasileira atinente ao tema.

A sistematização aqui realizada traz à tona, em sentido amplo, leituras de vida em sociedade no Brasil à luz da cidadania deliberativa, a partir de empregos de tal expressão no âmbito dos estudos em gestão social, o lócus privilegiado da intersubjetividade de uma gestão solidária (TENÓRIO, 1998), de relações dialógicas entre cidadãos que vivenciam processos decisórios em organizações. Constitui, assim, uma contribuição aos estudos da cidadania no Brasil, ao evidenciar aplicações, possibilidades, avanços e dilemas de práticas de cidadania deliberativa em organizações públicas não estatais. Dito de outro modo, encontra-se, aqui, um recorte do estágio em que se encontra o debate brasileiro em torno de experiências de gestão social, de processos dialógicos fundados na noção de cidadania deliberativa.

Após esta introdução, o artigo destaca os principais conceitos de Jürgen Habermas e discussões a respeito da cidadania deliberativa na gestão social. 0 texto prossegue com a exposição dos procedimentos metodológicos empregados na revisão da literatura, originários de buscas nas bases de dados Periódicos Capes e Google Acadêmico. A análise dos resultados, na 
sequência, sintetiza o perfil dos 18 textos coletados e o modo como preceitos habermasianos são incorporados a estudos em gestão social, com destaque para o constructo cidadania deliberativa. Como conclusão, fica evidente a opção dos autores por abordagens qualitativas, estando 7 textos publicados sob a forma de ensaios teóricos e 11 como exercícios teórico-empíricos em espaços colegiados de gestão, com predomínio em territórios e em conselhos de políticas públicas.

\section{APROXIMAÇÕES ENTRE GESTÃO SOCIAL E CIDADANIA DELIBERATIVA}

O conceito habermasiano de ação comunicativa, base da construção do termo gestão social conforme concebido por Tenório (1998), centra-se em um ato social que se refere à interação de pelo menos dois sujeitos, capazes de linguagem e ação, engajados em uma relação interpessoal (HABERMAS, 2011a). Para Habermas (2011b), a ação comunicativa pressupõe que a força da integração social abarca diversificados espaços públicos autônomos e procedimentos de formação democrática de opiniões e de vontades políticas. É, pois, da concepção de ação comunicativa, que advém o conceito habermasiano de mundo da vida. A ação comunicativa ocorre no mundo da vida, constituído por componentes estruturais cultura, sociedade e personalidade.

A ação comunicativa e o mundo da vida estão diretamente relacionados, uma vez que a primeira produz as estruturas simbólicas do segundo. Sob o aspecto do entendimento mútuo, a ação comunicativa serve para transmitir e renovar o saber cultural; sob o aspecto da ação, ela propicia a integração social e criação de solidariedade; e sob o aspecto da socialização, contribui com a formação da personalidade individual. No mundo da vida, a reprodução simbólica ocorre por intermédio da integração social.

Para Habermas, há três modelos normativos de democracia que podem ser relacionados a tipos ideais de cidadão, como aponta Tenório (1998): a) cidadão liberal, que possui direitos emanados do Estado em favor de interesses privados estabelecidos por lei; b) cidadão republicano que, além de utilizar sua liberdade para interesses privados, utiliza-se da participação como prática comum de modo a se converter em ator político em uma sociedade; e c) cidadão que pratica o modelo da deliberação, que, uma vez guiado pela racionalidade comunicativa, zela pelo entendimento e pelo consenso, por meio da argumentação fundamentada na própria estrutura da comunicação linguística. O modelo da deliberação "apoia-se precisamente em condições de comunicação nas quais o processo político pode ter a seu favor a presunção de gerar resultados racionais, porque, nele, o modo e o estilo da política deliberativa se realizam em toda a sua amplitude" (HABERMAS, 1995, p. 45). O conceito de cidadania deliberativa, assim concebido, foi incorporado na literatura brasileira por Tenório (1998), originalmente, a partir do artigo "Gestão social: uma perspectiva conceitual".

O texto pioneiro de Tenório (1998) pautou a gestão social tanto no âmbito dos governos, sobretudo na implementação de políticas públicas, quanto de organizações privadas no gerenciamento de negócios. Então, a gestão social foi concebida como processo gerencial dialógico em que o poder decisório é compartilhado entre os participantes de dada ação em qualquer tipo de sistema social - público, privado ou organizações do terceiro setor (TENÓRIO, 1998). Mais tarde, Tenório (2005) anotou que o modelo de democracia da cidadania deliberativa de Habermas é fundamentado na correlação entre direitos humanos e soberania popular e na reinterpretação da autonomia nos moldes da teoria do discurso. Tal compreensão incorpora a intersubjetividade de processos de entendimento (HABERMAS, 1995) que se realizam na forma institucionalizada de deliberações, nas instituições parlamentares ou nas redes de comunicação dos espaços públicos políticos. Por esse caminho, Tenório (1998, p. 18-19) defende que o modelo de cidadania deliberativa representa a

[...] verdadeira gestão social [...] na qual o indivíduo deve participar de um procedimento democrático, decidindo, nas diferentes instâncias de uma sociedade e em diferentes papéis, seu destino social como pessoa [...], ou seja, sua autodeterminação não se dá sob a lógica do mercado, mas da democracia social: igualdade política e decisória.

Para Tenório (1998, p. 19), é no terceiro setor que tal ambiente se mostra útil, uma vez que reside no âmbito das organizações da sociedade civil "o [lócus] privilegiado da integração social, da intersubjetividade pleiteada por uma gestão mais solidária".

A cidadania, então, exige uma identidade política adequada para aglutinar diferentes grupos e favorecer certa identidade coletiva para o conjunto dos indivíduos pertencentes a determinada comunidade, o que reforça a presença de princípios e loci do domínio da gestão social, da gestão das organizações da sociedade civil, do chamado terceiro setor. Afirma Tenório $(2005$, p. 102) que o adjetivo social qualificando o substantivo gestão pode ser "entendido como o espaço privilegiado de 
relações sociais em que todos têm o direito à fala, sem qualquer tipo de coação". Assim, gestão social, quando relacionada a temas que envolvem o aparelho burocrático público, torna-se processo de tomada de decisão que ocorre na esfera pública, lugar onde interagem sociedade e Estado com o objetivo de promover uma administração pública ampliada (TENÓRIO, 2010).

A esfera pública se apresenta como espaço de intermediação entre Estado, sociedade e mercado - e cidadania deliberativa, processo participativo de deliberação baseado essencialmente no entendimento (e não no convencimento ou na negociação) entre as partes. O procedimento da prática da cidadania deliberativa na esfera pública é a participação (TENÓRIO, 2008a), o que requer o agir comunicativo de Habermas. Por essa razão, Tenório (2008a) defende que a gestão social deve ser orientada pela racionalidade comunicativa, em um contexto no qual os atores, ao fazerem propostas, não podem impor pretensões de validade sem que haja um acordo alcançado comunicativamente, com todos os participantes expondo argumentos para debate ou em torno de certo projeto em construção.

É relevante considerar que, sob condições adequadas ao exercício da cidadania deliberativa, o cidadão não usa a liberdade em proveito e defesa de interesses privados exclusivamente, mas, também, como exercício que lhe permite converter-se no que pretende ser, ente político responsável por uma comunidade de pessoas livres e iguais (HABERMAS, 1995). A gestão social persegue princípios semelhantes, pois, "enquanto a gestão estratégica procura objetivar o 'adversário' através da esfera privada, a gestão social deve atender, por meio da esfera pública, ao bem comum da sociedade" (TENÓRIO, 2006, p. 11471148). Estão postas, assim, noções de comunidades de pessoas livres e iguais que, na esfera pública, promovem o bem comum da sociedade. É esta, pois, a interseção que este texto reconhece e que justifica o exercício teórico aqui realizado, qual seja, o de qualificar o modo como se apresentam, no domínio da gestão social, preceitos habermasianos de cidadania deliberativa.

Outros autores brasileiros abordam gestão social seguindo bases similares - lócus colegiados de deliberação, processo destinado a atingir fins e interesses emancipatórios da sociedade, práticas de conhecimentos compartilhados e tomada de decisão coletiva baseada na inelegibilidade da linguagem. Em França Filho $(2003,2008)$, a gestão social assume duas abordagens: como processo (nível organizacional) e como fim (nível macro - problemática de sociedade). Fischer (2002), por sua vez, utiliza o termo gestão do desenvolvimento social, tomado como espaço reflexivo de práticas e de conhecimentos constituídos por múltiplas disciplinas. Carrion (2007) toma outro alvo, o "local”, considerado lócus privilegiado para a gestão social, não apenas no âmbito geográfico, mas, fundamentalmente, nas particularidades culturais e identitárias de cada comunidade, uma vez que a gestão social tem como foco a mudança da morfologia do social em uma perspectiva de desenvolvimento local integrado.

Cançado (2011) toma gestão social como processo, a partir da tomada de decisão coletiva, sem coerção, baseada na inteligibilidade da linguagem, na dialogicidade e no entendimento esclarecido como processo, na transparência como pressuposto e na emancipação como fim. $\mathrm{O}$ autor entende que a gestão social parte do interesse bem compreendido (IBC), ocorre na esfera pública e tem por objetivo a emancipação. Souza e Oliveira $(2006$, p. 60) seguem igualmente pelo viés da tomada de decisão e da emancipação, definindo a gestão social como

[...] conjunto de estratégias e políticas organizacionais de promoção do bem-estar de indivíduos e coletividades, destinado à recomposição de elos de integração do Homem com o semelhante e com o ambiente, articulando, sob o ideal da emancipação humana, elementos de racionalidade substantiva à ação racional instrumental.

Entre os autores, é nítida a opção defendida por Jürgen Habermas de uma noção de tomada de decisão fundamentada em elementos de racionalidade substantiva, ainda que intercedida por racionalidade instrumental, como pontuam Souza e Oliveira (2006).

Como fim, ou seja, como problemática da sociedade (FRANÇA FILHO, 2003, 2008), a gestão social tende a assumir propósitos de emancipação mediante exercícios de participação. A gestão social é, portanto, fim (busca por emancipação) e processo intersubjetivo, dialógico, que ocorre em espaço social, na esfera pública, articulando diferentes atores da sociedade civil, ora em interação com o Estado, ora em interação com o mercado, ora os três conjuntamente. Em sentido similar, Tenório (2008a, 2008b), ao tomar como base os constructos cidadania deliberativa e agir comunicativo, de Habermas, atribui um caráter democrático à gestão social, com a decisão ocorrendo pela via do entendimento e não da negociação, com a finalidade de promover o bem comum. Reside, pois, nesse ponto, o componente central da aproximação entre gestão social e cidadania deliberativa, caminho adotado, de um ou outro modo, por autores brasileiros, como se constata tanto nesta síntese quanto na análise das informações desta pesquisa, apresentada adiante. 
A gestão social tem sido objeto de estudo e práticas associadas a arranjos da sociedade civil, de monitoramento e avaliação de políticas sociais, em colegiados voltados ao combate à pobreza e em temas de sustentabilidade e meio ambiente e são esses os vieses que aparecem nesta revisão, notadamente em colegiados territoriais e de controle de políticas públicas. A discussão de uma gestão democrática, participativa, quer na formulação de políticas públicas, quer nas relações de caráter produtivo (TENÓRIO, 2008c), não aparece nas abordagens aqui consideradas. Segue esta revisão, portanto, uma tendência de que não se consegue dar conta do potencial teórico e analítico do próprio termo (CANÇADO, TENÓRIO e PEREIRA, 2011), uma vez que abordar gestão social é pensar para além da gestão de políticas públicas, uma vez que o campo social possibilita estabelecer articulações entre ações de intervenção e de transformação por meio de uma diversificada gama de atores.

\section{PROCEDIMENTOS METODOLÓGICOS}

O protocolo Prisma orientou a realização desta revisão sistemática. Ele é apresentado em 27 itens e um fluxograma de 4 etapas e tem o propósito de contribuir para que autores aprimorem relatos de revisões sistemáticas e meta-análises (GALVÃO, PANSANI e HARRAD, 2015). A sistematização partiu de busca de textos mediante o uso dos descritores "cidadania deliberativa" e "gestão social", conjuntamente, sem critério de temporalidade. Dois procedimentos foram aplicados com o propósito de localizar a produção intelectual pretendida: a) busca preliminar na base Periódicos Capes por textos escritos em português, exclusivamente, na área de concentração/avaliação Administração Pública, Administração, Ciências Contábeis e Turismo; e b) busca confirmatória no Google Acadêmico. A busca foi realizada em junho de 2017.

A primeira busca, na base Periódicos Capes, gerou 17 registros e a segunda, no Google Acadêmico, 4. A partir das 2 coletas adveio a aplicação dos critérios de seleção e exclusão, o que contemplou: a) exclusão de duplicidades; b) alinhamento do conteúdo do material selecionado com o problema desta revisão; e c) compatibilização do material coletado nas buscas. Com base em tais critérios, foram excluídos 3 registros do resultado preliminar da busca na base Periódicos Capes -2 por duplicidade e 1 pelo fato de não se enquadrar o conteúdo no propósito desta revisão - foi este o caso do texto de Silva, Lima e Gomide et al. (2017).

Concluídos os procedimentos de busca e seleção, inclusão/exclusão, o passo seguinte ocorreu com auxílio do Computer Assisted Qualitative Data Analysis (CAQDAS) gerenciador de referências bibliográficas Zotero 5.0 para o ordenamento dos textos coletados. A sequência contemplou a sumarização do material coletado em planilha no software Microsoft Excel com as informações: título; Qualis; volume; número e ano de publicação; autor e vinculação institucional; resumo e palavras-chave do texto; número de referências e citações; problema e objetivo; autores mais citados; base teórica e contexto de aplicação; identificação da abrangência do público e critério de seleção de sujeitos; tipo da pesquisa e enquadramento epistemológico; enquadramento metodológico; procedimentos de coleta e análise; e principais conclusões.

Os dados foram processados no CAQDAS VOSViewer, com o propósito de definição da rede de autorias, e no site Nube de Palabras (2017), para identificação de palavras mais citadas nos títulos. Diagramada em duas etapas (processo de triagem e processo de análise), a Figura 1 sintetiza a trajetória da revisão realizada ladeada pelo respectivo resultado alcançado em cada fase (4 de triagem e 5 de análise). 
Figura 1

Síntese do processo de revisão sistemática

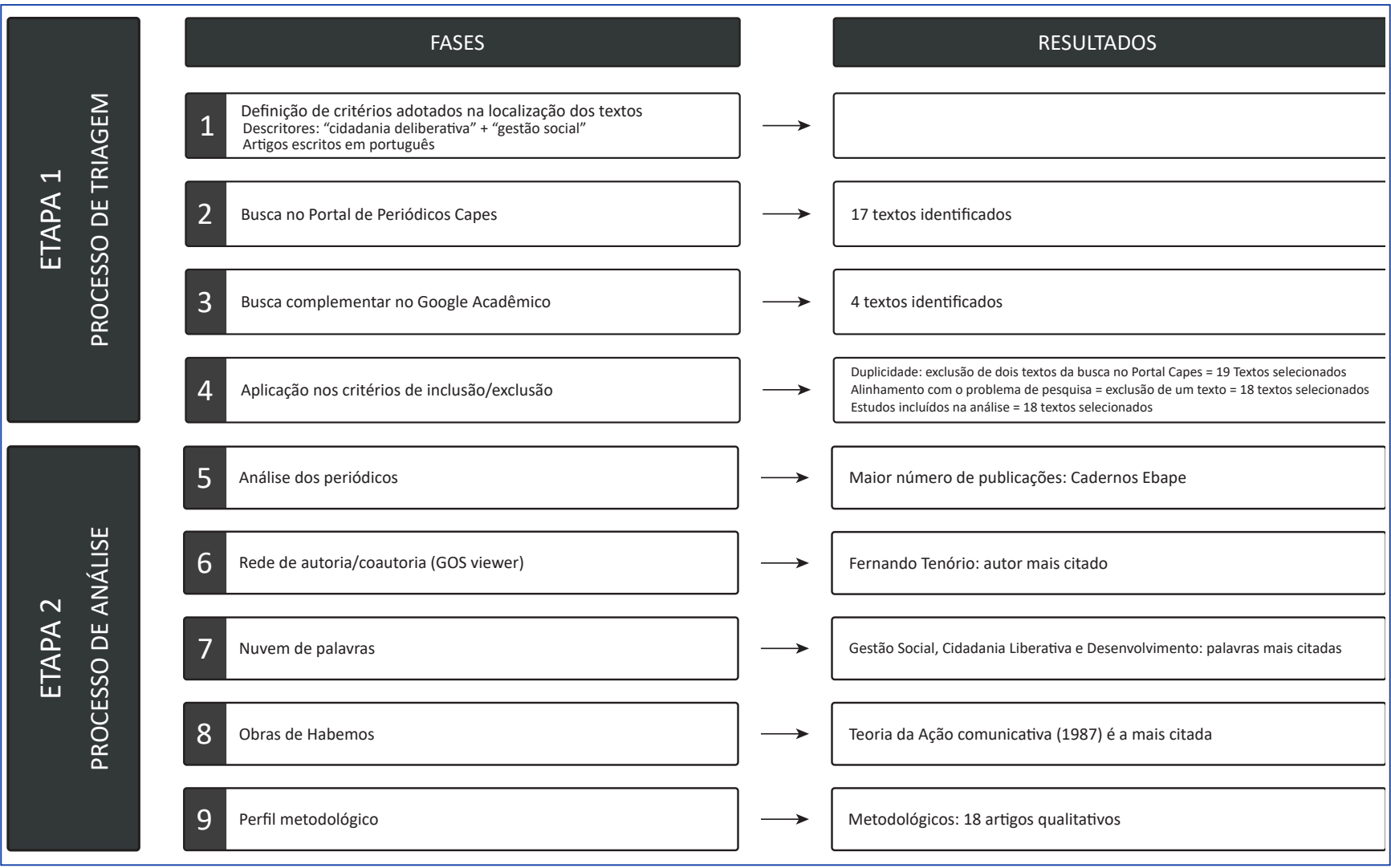

Fonte: Elaborada pelos autores.

\section{ANÁLISE DOS RESULTADOS}

O Quadro 1 assinala que o Cadernos EBAPE.BR é o periódico que concentra a maior quantidade de publicações, contabilizando 6 artigos, também havendo publicações em outros meios, igualmente com projeção nacional. Dos 18 registros, 9 estão publicados em periódicos com classificação Qualis A2, ao passo que a outra metade se encontra em periódicos com classificação Qualis B1 a B4. A primeira publicação com os descritores gestão social e cidadania deliberativa data de 1998, tendo como autor Fernando Guilherme Tenório. A segunda publicação veio somente em 2005, 7 anos mais tarde. Advieram, então, em 2009 e 2010, mais uma publicação a cada ano. O ano de 2011 registra avanço significativo, com 6 publicações. Após esse ano houve declínio de publicações nos descritores mencionados.

Em 2011 o Cadernos EBAPE.BR lançou uma edição especial com 11 artigos sobre Gestão Social e isso explica o aumento significativo dos descritores pesquisados nesse ano, especificamente. Entre os 11 artigos da edição especial, 5 utilizaram os descritores cidadania deliberativa e gestão social. Esse resultado é coerente com a própria construção do campo de gestão social, que tem como constructos o modelo de deliberação, esfera pública e ação comunicativa de Jürgen Habermas. As publicações mais recentes (três) datam de 2015. 
Quadro 1

Síntese da produção por periódico, Qualis e ano

\begin{tabular}{|c|l|c|c|}
\hline Código & \multicolumn{1}{|c|}{ Título do periódico } & Qualis & Ano \\
\hline 1 & Revista de Administração Pública & A2 & 1998 \\
\hline 2 & Desenvolvimento em Questão & B2 & 2005 \\
\hline 3 & Revista de Administração Pública & A2 & 2009 \\
\hline 4 & Cadernos EBAPE.BR & A2 & 2010 \\
\hline 5 & Cadernos EBAPE.BR & A2 & 2011 \\
\hline 6 & Cadernos EBAPE.BR & A2 & 2011 \\
\hline 7 & Desenvolvimento Regional em Debate & B4 & 2011 \\
\hline 8 & Cadernos EBAPE.BR & A2 & 2011 \\
\hline 9 & Cadernos EBAPE.BR & A2 & 2011 \\
\hline 10 & Cadernos EBAPE.BR & A2 & 2011 \\
\hline 11 & Revista de Administração Pública & A2 & 2012 \\
\hline 12 & Revista Pensamento \& Realidade & B3 & 2012 \\
\hline 13 & Desenvolvimento Regional em Debate & B4 & 2013 \\
\hline 14 & Revista de Administração Mackenzie & B1 & 2013 \\
\hline 15 & Revista Brasileira de Gestão e Desenvolvimento Regional & B1 & 2013 \\
\hline 16 & Revista de Ciências da Administração & B1 & 2015 \\
\hline 17 & PRAcs: Revista Eletrônica de Humanidades do Curso de Ciências da Unifap & B3 & 2015 \\
\hline 18 & Revisão de Gestão USP & B1 & 2015 \\
\hline
\end{tabular}

Fonte: Elaborado pelos autores.

A maior parte dos autores está vinculada a universidades públicas, com 2 autores de instituições particulares - Fernando Guilherme Tenório, da Fundação Getulio Vargas (FGV), e Sérgio Luís Allebrandt, da Universidade Regional do Noroeste do Estado do Rio Grande do Sul (Unijuí). São 42 autores e coautores de 19 instituições. Ainda que presente em todas as regiões, o tema não alcança todas as unidades da Federação, aparecendo em apenas 8 (São Paulo, Rio de Janeiro, Minas Gerais, Bahia, Distrito Federal, Tocantins, Rio Grande do Sul e Santa Catarina). Embora alcance praticamente toda a região Sudeste, vale ressaltar que a maioria dos autores está vinculada a instituições de Ensino Superior (IES) do Rio Grande do Sul. A rede de autorias e coautorias, gerada com apoio do software VOSViewer, contribui para explicar a relação entre eles. Os artigos geraram 12 clusters, com destaque para os autores Fernando Guilherme Tenório (FGV) e José Roberto Pereira (Universidade Federal de Lavras - UFLA), em uma rede que ocorre por derivação, e Sérgio Luís Allebrandt (Unijuí). 
Figura 2

Clusters de autoria dos artigos

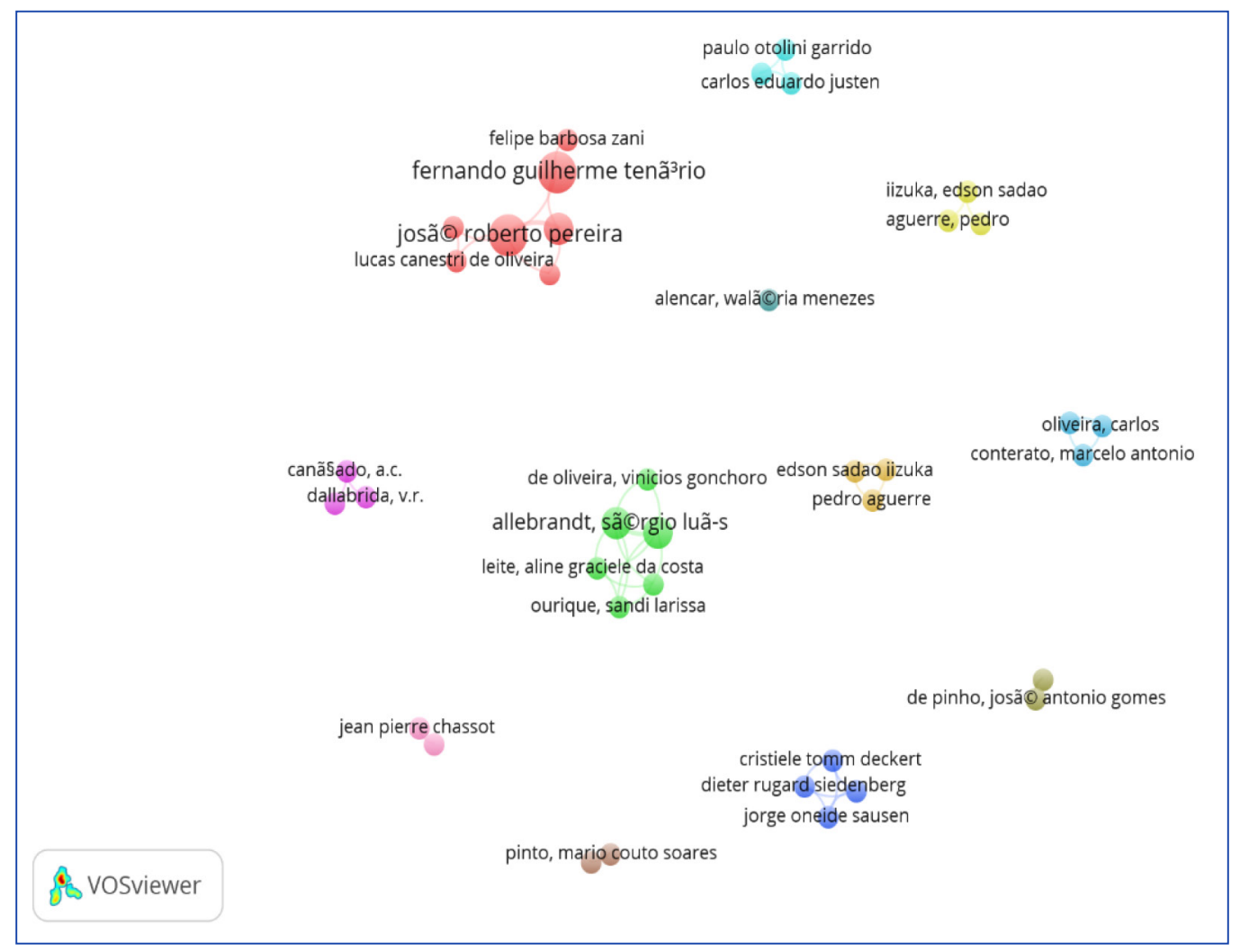

Fonte: Elaborada pelos autores.

Os títulos dos artigos foram processados no site Nube de Palabras (2017), com o propósito de identificação das palavras que aparecem com maior frequência. As palavras "Gestão" e "Social" aparecem 18 vezes cada, garantindo que os textos abordam gestão social como constructo central. O mesmo fenômeno não ocorre com "cidadania deliberativa", uma vez que ocorre o emprego de expressões próximas extraídas da literatura habermasiana, a exemplo de participação, democracia deliberativa e ação comunicativa. Desse modo, a palavra "cidadania" aparece 6 vezes e "deliberativa", 3. A palavra "desenvolvimento" também aparece 6 vezes. As palavras "participação", "territorial", "territórios", "reflexões", "análise", "estudo" e "caso" aparecem em 2 títulos cada. 
Figura 3

Nuvem de palavras com o título dos artigos

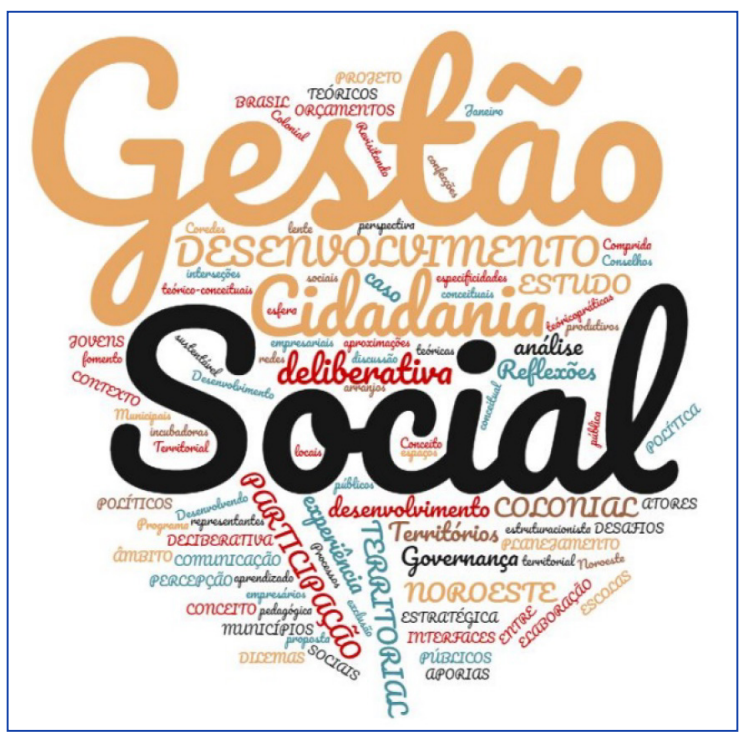

Fonte: Elaborada pelos autores.

Os objetivos dos artigos indicam concentração em análises qualitativas, com 7 trabalhos caracterizados como ensaios teóricos e os outros 11 como trabalhos empíricos, desenvolvidos principalmente em territórios e conselhos regionais. Tenório é citado em todos os artigos analisados. Do referido autor, entre os artigos aqui considerados, "Gestão social: uma perspectiva conceitual" é citado em 276 publicações e "(Re)visitando o conceito de gestão social", em 192. A maioria dos textos analisados retoma o conceito de gestão social de Tenório (2005) em inserções com o propósito de estabelecer contraponto ao conceito de gestão estratégica (IIZUKA, GONCALVES-DIAS e AGUERRE, 2012), de pautar determinada orientação para a racionalidade comunicativa (OLIVEIRA, PERAFÁN e CONTERATO, 2013) e de assumir a racionalidade substantiva em sentido similar à abordagem adotada por Guerreiro Ramos (1981), como no caso de Allebrandt, Benso e Oliveira (2015). Outros autores - Airton Cançado, Genauto França Filho, Tânia Fischer e Valdir Dallabrida - são citados para menção ao conceito de gestão social.

O campo de conhecimento da gestão social aparece, nos artigos analisados, fundamentado em 3 grandes categorias articuladas entre si: interesse público, esfera pública e emancipação social (PERES JÚNIOR, PEREIRA e OLIVEIRA, 2013). Genauto França Filho aproxima os conceitos de gestão pública, gestão estratégica e gestão social como forma de compreendê-los e buscar o significado deste último, que é entendido pelo autor, como anteriormente registrado, sob 2 perspectivas: como processo - relacionado ao nível organizacional - e como fim - relacionado ao nível macro e à problemática de sociedade (CANÇADO, TAVARES e DALLABRIDA, 2013). Outra vertente de estudo que se destaca no campo da gestão social é a abordagem organizacional interdisciplinar, de Tânia Fischer, que argumenta que, a partir da articulação das organizações, em interorganizações que constroem certa realidade social e promovem desenvolvimento de modo integrado, a gestão social passa a abordar uma gestão do desenvolvimento social, caracterizada por parcerias, redes, consórcios, clusters, arranjos socioprodutivos, entre outras variações similares (PERES JÚNIOR, PEREIRA e OLIVEIRA, 2013).

Os estudos de Valdir Dallabrida relacionam gestão social a um enfoque do desenvolvimento territorial (CANÇADO, TENÓRIO e PEREIRA, 2011), aproximando-se de Tânia Fischer e destacando a rede de governança como coordenação e ações cooperativas entre atores sociais, econômicos e institucionais que expressam capacidades de um território para gerir assuntos públicos (ALLEBRANDT, BENSO e OLIVEIRA, 2015). Na maioria dos textos analisados, os autores fazem uso de conceitos habermasianos. Desse modo, o Quadro 2 expressa as principais obras de Habermas citadas, assim como os respectivos trabalhos que se apoiam em conceitos do autor. A Teoria da ação comunicativa é a obra de Habermas mais referenciada e dentre os conceitos associados se encontram cidadania deliberativa, agir comunicativo e racionalidade comunicativa. Isso evidencia que a forma como os autores utilizam o conceito de cidadania deliberativa na gestão social converge com a forma pela qual o conceito é utilizado nas obras habermasianas, como apresentado na introdução e no referencial teórico deste estudo. 
Quadro 2

Classificação das obras citadas de Habermas por artigo contemplado na análise

\begin{tabular}{|l|c|}
\hline \multicolumn{1}{|c|}{ Obras de Habermas citadas } & Artigos (código* \\
\hline Teoria da ação comunicativa (2011a; 2011b) & $11,16,3,1$ \\
\hline Três modelos normativos de democracia (1995) & 14,1 \\
\hline Direito e democracia: entre facticidade e validade (1997) & 18,02 \\
\hline $\begin{array}{l}\text { Mudança estrutural da esfera pública: investigações quanto a uma } \\
\text { categoria da sociedade burguesa (2003) }\end{array}$ & 4,15 \\
\hline Teoria e práxis: estudos de filosofia social (2011) & 1 \\
\hline La necesidad de revisión de la izquierda (1991) & 1 \\
\hline
\end{tabular}

Fonte: Elaborado pelos autores.

* Conforme a ordem dos textos no Quadro 1.

lizuka, Gonçalves-Dias e Aguerre (2012) utilizaram fundamentos da cidadania deliberativa para embasar estudo no Território da Cidadania Litoral Sul da Bahia, como modo de compreender fatos, diálogos e eventos inesperados e não lineares que são, na maioria das vezes, ignorados por boa parte da literatura administrativa tradicional, mas que, por outro lado, podem ser analisados à luz de tal constructo. A concepção do agir comunicativo foi utilizada por Allebrandt, Benso e Oliveira (2015) para compreender em que medida a comunicação do Programa Territórios da Cidadania propicia espaço de diálogo entre as organizações que buscam, por meio de tal iniciativa pública, realizações sociais, políticas, econômicas, culturais e ecológicas. Villela e Pinto (2009) fazem relação entre os conceitos de governança e racionalidade comunicativa na abordagem de vínculos democráticos em relações sociais que devem ser dialógicas, e não monológicas, quando destinadas ao suprimento de dificuldades encontradas em redes empresariais (e não propriamente em redes do âmbito da gestão social).

Três modelos normativos de democracia (HABERMAS, 1995) é citado em 2 artigos que também fazem referência ao conceito de cidadania deliberativa, assim como ao de esfera pública. Entre estes está Tenório (1998), que ressalta o modelo de cidadania deliberativa como proposta que Habermas defende em contraposição aos modelos liberal e republicano, pois tal concepção de cidadania tem base em racionalidade comunicativa. Peres Júnior, Pereira e Oliveira (2013) utilizam, por sua vez, o conceito de esfera pública, fazendo comparação com o arcabouço teórico da Teoria da Estruturação. Os autores argumentam que a dualidade da estrutura a torna, ao mesmo tempo, meio e resultado da ação. Além disso, fornecem subsídios à compreensão de práticas de sistema deliberativo e formação da esfera pública reconhecendo que a ação humana pode assumir natureza intencional, reflexiva e cognoscitiva.

A obra Direito e democracia: entre facticidade e validade foi citada por Tenório (2005) e Pinho e Santos (2015). Tenório (2005) enfatiza que, diferentemente de um processo centralizador, no qual o conhecimento técnico é o principal argumento da decisão, sob uma perspectiva descentralizadora a esfera pública deve identificar, compreender, problematizar e propor soluções para os dilemas da sociedade a ponto de estas serem assumidas como políticas públicas pelo contexto parlamentar e executadas pelo aparato administrativo de governo. Pinho e Santos (2015) criticam analogias procedidas por Tenório destacando que dilemas de natureza teórica e política conduzem à constatação de que não existem justificativas teóricas consistentes que fundamentem a associação entre gestão social, emancipação e esfera pública, (particularmente nas adaptações teóricas de democracia deliberativa habermasiana realizadas por Tenório). Para Pinho e Santos (2015), o debate suscitado por Tenório, associando gestão social e esfera pública, aponta que, no atual contexto econômico e social brasileiro, a economia é um requisito da democracia, em qualquer das duas modalidades, continuando a valer, assim, a clássica formulação de que a democracia diz respeito à liberdade, mas também à igualdade.

Oliveira, Cançado e Pereira (2010) e Cançado, Tavares e Dallabrida (2013) citam a obra Mudança estrutural da esfera pública: investigações quanto a uma categoria da sociedade burguesa (HABERMAS, 2003) para tratar da existência de uma multiplicidade de visões para os significados de público e esfera pública de Habermas, esclarecendo que, somente com o surgimento do Estado moderno é que as categorias de público e privado passaram a ter efetiva aplicação processual jurídica, sendo esse momento o marco a partir do qual o conceito de esfera pública passa a representar uma possibilidade de sistematização da sociedade em uma de suas categorias centrais. 
As obras Teoria e práxis: estudos de filosofia social (HABERMAS, 2011) e A necessidade de revisão da esquerda (HABERMAS, 1991) são citadas apenas por Tenório (1998). Em relação à primeira obra, Tenório (1998) aborda a proposta de Habermas de elaborar uma teoria da sociedade que, diferentemente da teoria tradicional, positivista, possibilita uma práxis social voltada ao conhecimento reflexivo e a uma política questionadora das estruturas sócio-político-econômicas existentes, propondo uma teoria que livre o homem de dogmatismos e que contribua para sua emancipação. No que diz respeito à segunda obra, Tenório (1998) menciona a argumentação como procedimento para solução de problemas, sendo ela um tipo de fala em que os participantes de determinada ação tematizam pretensões de validade e tratam de implementá-las ou de recusá-las por meio de argumentos.

No que concerne à análise da base epistemológica foi investigada a relação dos artigos com os paradigmas de Burrel e Morgan (1979): funcionalismo; interpretativo; humanismo radical; estruturalismo. Há predominância da abordagem interpretativista, presente em 16 artigos. Os outros 2 podem ser classificados no paradigma humanista radical e no paradigma estruturalista radical. Apesar de Cançado (2011) caracterizar e aproximar o campo de conhecimento da gestão social do paradigma humanismo radical, os estudos analisados têm aproximações com o domínio interpretativista. $O$ viés interpretativista fica evidente quando os artigos assumem trajetórias de perceber empiricamente o mundo social como criado pelos envolvidos. Abordam assuntos que permeiam a gestão social e a cidadania deliberativa relacionados a consenso, integração, solidariedade, cooperação e participação, mas sem avançar em questões como status quo e emancipação, bases do humanismo radical e da perspectiva teórico-crítica da Escola de Frankfurt. De outra forma, é nítido o fato de que os estudos se distanciam do caráter instrumental, pragmático e funcionalista hegemônico no domínio da ciência da administração, como denunciado por Guerreiro Ramos (1981).

Todos os artigos têm natureza metodológica qualitativa. Esse achado guarda sintonia com a base epistemológica e com o campo de estudos da gestão social, uma vez que o paradigma interpretativista assume análises intersubjetivas, relação importante na ação comunicativa de Jürgen Habermas e no campo da gestão social. A predominância de abordagem metodológica qualitativa evidencia o interesse dos autores pela exploração dos fenômenos estudados com maior profundidade e com foco em vivências, em sujeitos. Essa abordagem condiz com uma gestão social orientada pela racionalidade comunicativa e cidadania deliberativa, onde as decisões são tomadas por meio do diálogo, do conhecimento, ou seja, discursivamente e o sujeito e suas vivências são fontes importantes no processo de construção do conhecimento. A abordagem qualitativa está igualmente relacionada ao caráter metodológico ideográfico da gestão social, quando permite que o sujeito-pesquisador revele sua própria natureza durante a pesquisa. Por essa razão, torna-se pertinente acatar o entendimento de que procedimento metodológico quantitativo, que se pauta na utilização de métodos das ciências naturais (construções de testes de hipóteses e análise quantitativa de dados), não permite que se percebam nuances da gestão social (CANÇADO, 2011).

Dos 18 artigos, 7 têm abordagem exclusivamente teórica. A presença de pesquisa teórica em uma ciência deve ser considerada fator positivo, uma vez que, por meio dela, a literatura é constantemente revisada, entrelaçada e, consequentemente, aprimorada, a ponto de gerar novos conceitos ou constructos e até novas teorias. Essa é a realidade do campo da gestão social, que, como evidenciam estudos atuais, ainda provoca constantes e enriquecedores debates e discussões que buscam sua consolidação. Predominam "Estudo de caso" (6) e "Pesquisa documental" (6), como aponta a Tabela 1.0 estudo de caso está presente nos estudos teórico-empíricos que, majoritariamente, teve como objeto de análise conselhos e colegiados territoriais, entendidos como espaços que permitem a participação da sociedade na elaboração, na implementação e no controle de políticas públicas. Ao levar em consideração a pluralidade de formas de comunicação e discussão, em que as formas de deliberação garantem a participação em igualdade de condições na formulação e implementação de políticas públicas, esses espaços possibilitam a prática da cidadania deliberativa habermasiana (assim entendem os autores).

A técnica de coleta de dados mais utilizada foi a entrevista (9), o que mostra que as pesquisas em gestão social, em interface com cidadania deliberativa, têm sido pautadas pela construção do conhecimento baseada em experiências e percepções de diferentes sujeitos e grupos sociais com atuação na esfera pública. Há apenas 2 técnicas de análise: "Análise de conteúdo"; e "Análise intersubjetiva". Tais procedimentos estão em sintonia com as principais formas de coleta de dados. Apesar da análise intersubjetiva ter sido aplicada em apenas um estudo, ela intermedeia a maioria dos estudos teórico-empíricos encontrados. 
Tabela 1

\section{Perfil metodológico}

\begin{tabular}{|c|c|c|}
\hline \multirow{2}{*}{ Característica observada } & \multicolumn{2}{|c|}{ Descrição } \\
\hline & Elementos & Frequência \\
\hline \multirow{4}{*}{ Abordagem } & Qualitativo & 18 \\
\hline & Quantitativo & 0 \\
\hline & Misto (quali-quanti) & 0 \\
\hline & Total & 18 \\
\hline \multirow{8}{*}{ Método de coleta de dados } & Estudo de caso & 6 \\
\hline & Pesquisa documental & 6 \\
\hline & Levantamento de campo & 2 \\
\hline & Hermenêutica & 2 \\
\hline & Pesquisa bibliográfica & 2 \\
\hline & História oral & 2 \\
\hline & Metodologias participantes & 1 \\
\hline & Total & $20 *$ \\
\hline \multirow{7}{*}{ Técnicas de coleta de dados } & Entrevistas & 9 \\
\hline & Questionários & 4 \\
\hline & Documentação & 4 \\
\hline & Observação & 3 \\
\hline & Sensemaking & 1 \\
\hline & Grupo focal & 1 \\
\hline & Total & $22 *$ \\
\hline \multirow{3}{*}{ Técnicas de análise de dados } & Análise de conteúdo & 7 \\
\hline & Análise intersubjetiva & 1 \\
\hline & Total & 8 \\
\hline
\end{tabular}

Fonte: Elaborada pelos autores.

* A ocorrência em número maior do que o número de artigos analisados se dá em virtude de haver casos de uso simultâneo de duas modalidades/tipologias.

A leitura do constructo cidadania deliberativa contribui para o debate teórico e empírico nos trabalhos analisados no campo da gestão social. Os textos teóricos indicam que o constructo é base relevante para a construção do domínio desse campo e as pesquisas empíricas mostram tal aplicabilidade, indicando que o processo de cidadania deliberativa habermasiana pode constituir estratégia necessária para a institucionalização do campo. As pesquisas em territórios rurais revelam que a gestão social e a cidadania deliberativa podem constituir estratégias de desenvolvimento territorial sustentável por meio da participação de diferentes atores na elaboração e implantação de políticas públicas (IIZUKA, GONÇALVES-DIAS e AGUERRE, 2012); na promoção de uma comunicação que visa à participação da sociedade (ALLEBRANDT, BENSO e OLIVEIRA, 2015); assim como também pela compreensão de que o processo de cidadania deliberativa é permeado por diversos fatos, diálogos e eventos inesperados e não lineares (IIZUKA, GONÇALVES-DIAS e AGUERRE, 2011).

As pesquisas em conselhos de desenvolvimento também mostram como estes produzem mudanças na perspectiva pública dos indivíduos, na cultura da sociedade civil, no perfil da sociedade política e no modus operandi do aparelho burocrático e dos governos (ALLEBRANDT, SIEDENBERG, SAUSEN et al., 2011). Além disso, também conduzem processos de tomada de decisão descentralizada, sendo espaços de consecução de uma gestão envolvente, na tentativa de mobilizar cada vez mais a sociedade (CHASSOT e ALLEBRANDT, 2016). Assim, fica claro que o diálogo e a participação dos atores na elaboração e implantação de políticas públicas são imprescindíveis quando se almeja promover transformações em fenômenos sociais. 
Os artigos teóricos assumem que a gestão social é domínio em construção e, por essa razão, caminham para fornecer ideias e inquietações para a consolidação do campo. Os autores consideram a gestão social alternativa teórica e prática ao pensamento organizacional hegemônico. Indicam que o tema está fortemente relacionado a temáticas do aparelho burocrático público e ao processo de tomada de decisão que ocorre na esfera pública, quando atores da sociedade civil e do Estado interagem com o objetivo comum de promover uma administração pública ampliada. Tais espaços só têm significado - na perspectiva da gestão social e da cidadania deliberativa - se os interessados participarem do processo de tomada de decisão. A sociedade brasileira tem (re)criado espaços em que a ação pública se torna possível por meio do diálogo, da participação, da cidadania deliberativa, e, assim, ao sinalizar que a esfera pública constitui base para se compreender e consolidar fenômenos no âmbito da ciência administrativa, os autores definem um lócus para a gestão social no conhecimento científico.

\section{CONSIDERAÇÕES FINAIS}

Esta revisão sistematiza o modo como o conceito habermasiano de cidadania deliberativa é aplicado em estudos de gestão social no Brasil. Os resultados mostram que, dos 18 artigos coletados, 9 estão publicados em periódicos com classificação Qualis A2, ao passo que os outros 9 estão em periódicos com classificação entre Qualis B1 e B4. O periódico Cadernos EBAPE.BR é o que concentra maior volume de publicações com os descritores cidadania deliberativa e gestão social, conjuntamente, contabilizando 5 registros. A primeira publicação com os descritores data de 1998 (Fernando Guilherme Tenório, Revista de Administração Pública) ao passo que 2011 é o ano com maior número de publicações (6). As publicações mais recentes datam de 2015 (3).

Em relação à abordagem metodológica, predominam análises qualitativas e 7 artigos são caracterizados como ensaios teóricos. Os outros 11 são trabalhos empíricos, desenvolvidos principalmente em colegiados territoriais e conselhos de políticas públicas. $\mathrm{O}$ autor Fernando Guilherme Tenório é citado em todos os artigos analisados. Além de cidadania deliberativa, outros conceitos de Habermas, como agir comunicativo, racionalidade comunicativa, esfera pública, participação e argumentação, servem de embasamento para abordagens democratizantes das relações sociais e, especialmente, para pautar ideais de emancipação humana. No que concerne à base epistemológica, predomina a abordagem interpretativista.

Os achados desta pesquisa evidenciam que a forma como os autores da gestão social utilizam o conceito de cidadania deliberativa no Brasil converge para o modo como o conceito é utilizado nas obras de Habermas, isto é, como sendo um tipo de cidadania embasado em um estilo político específico e em uma prática de democracia deliberativa, mediado por outros conceitos como agir comunicativo e racionalidade comunicativa. Com isso, conclui-se que a leitura original de Tenório (1998) foi mantida ao longo de 20 anos e, desse modo, o conceito de cidadania deliberativa se alinha ao de gestão social e contribuiu com o debate teórico e os estudos empíricos no campo das organizações da sociedade civil, especificamente em colegiados. Por outro lado, são escassos, no Brasil, estudos envolvendo gestão social e cidadania deliberativa mediante aplicação junto a organizações públicas estatais e setor privado - como sugeriu originalmente Tenório (1998). Os resultados dos artigos teórico-empíricos, por sua vez, trazem reflexões a respeito de desafios e oportunidades referentes à gestão social, indicando que o processo de cidadania deliberativa habermasiana pode constituir estratégia necessária para a consolidação do campo. De outro modo, os resultados dos artigos teóricos pontuam que a gestão social está em construção e, para tanto, fornecem elementos de referência para sua composição.

Como limitação deste exercício de revisão é oportuno destacar que apenas o conceito habermasiano de cidadania deliberativa foi utilizado como critério de seleção dos artigos e, assim, fica aqui a sugestão para que futuros estudos analisem outros conceitos habermasianos associados ao campo da gestão social. Outra possibilidade se refere ao emprego dos conceitos habermasianos em teses e dissertações no Brasil na área de administração, que pode revelar se e como Habermas é tomado em outros domínios da ciência administrativa para além da gestão social. Nesse sentido, é importante ressaltar que, no texto original de Tenório (1998), fica claro o entendimento de que a gestão social pode dar-se não só em organizações da sociedade civil, do terceiro setor, mas, também, em ambientes de tomada de decisão dialogada tanto em organizações públicas estatais quanto privadas. A partir das informações aqui processadas, tal viés não tem tido repercussão junto a pesquisadores brasileiros e esse fato merece atenção e aprofundamento. 


\section{REFERÊNCIAS}

ALLEBRANDT, S. L. et al. Gestão social e cidadania deliberativa: uma análise da experiência dos Coredes no Rio Grande do Sul, 1990-2010. Cadernos EBAPE.BR, v. 9, n. 3, p. 914-945, 2011.

ALLEBRANDT, S. L.; BENSO, A.; OLIVEIRA, V. G. Interfaces entre a comunicação e a gestão social no contexto do desenvolvimento territorial: um estudo do território da cidadania noroeste colonial do Rio Grande do Sul. Revista de Ciências da Administração, v. 17, n. 1, p. 120-133, 2015.

BURRELL, G.; MORGAN, G. Sociological paradigms and organizational analysis. London: Heinemann, 1979.

CANÇADO, A. C. Fundamentos teóricos da gestão social. 146 f. Tese (Doutorado em Administração) - Universidade Federal de Lavras, Lavras, 2011.

CANÇADO, A. C.; TAVARES, B.; DALLABRIDA, V. R. Gestão social e governança territorial: interseções e especificidades teórico-práticas. Revista Brasileira de Gestão e Desenvolvimento Regional, v. 9, n. 3, p. 313-353, 2013.

CANÇADO, A. C.; TENÓRIO, F. G.; PEREIRA, J. R. Gestão social: reflexões teóricas e conceituais. Cadernos EBAPE.BR, v. 9, n. 3, p. 681-703, 2011

CARRION, R. S. M. Gestão social: especificidades e práticas em discussão. In: SILVA, J. G. et al. (Org.). Tecnologias de gestão: por uma abordagem multidisciplinar. Vitória: Ed. Ufes, 2007. p. 108-124.

CHASSOT, J. P.; ALLEBRANDT, S. L. Processos de discussão em espaços públicos: a gestão social dos conselhos municipais de desenvolvimento do noroeste colonial do estado do Rio Grande do Sul. PRACS: Revista Eletrônica de Humanidades do Curso de Ciências Sociais da Unifap, v. 8, n. 2, p. 247-265, 2016.

FISCHER T. Poderes locais, desenvolvimento e gestão: uma introdução a uma agenda. In: FISCHER T. (Org). Gestão do desenvolvimento e poderes locais: marcos teóricos e avaliação. Salvador: Casa da Qualidade, 2002. p. 12-32.

FRANÇA FILHO, G. C. Gestão social: um conceito em construção. In: COLÓQUIO INTERNACIONAL SOBRE PODER LOCAL, 9., 2003, Salvador. Anais... Salvador: CIAGS/UFBA, 2003.

FRANÇA FILHO, G. C. Definindo gestão social. In: SILVA JÚNIOR, J. T. et al. (Org.). Gestão social: práticas em debate, teorias em construção. Fortaleza: UFC, 2008. p. 27-37.

FREITAG, B. A teoria crítica: ontem e hoje. 5. ed. São Paulo: Brasiliense, 1994.

GALVÃO, T. F.; PANSANI, T. S. A.; HARRAD, D. Principais itens para relatar revisões sistemáticas e meta-análises: a recomendação Prisma. Revista Epidemiologia e Serviços de Saúde, v. 24, n. 2, p. 335-342, 2015.

GARCIA, A. S. Esferas públicas como uma categoria fundante da gestão social. 273 f. Dissertação (Mestrado em Administração) Universidade Federal de Lavras, Lavras, 2016.

GUERREIRO RAMOS, A. A nova ciência das organizações: uma reconceituação da riqueza das nações. Rio de Janeiro: Ed. Fundação Getulio Vargas, 1981.
HABERMAS, J. Teoria do agir comunicativo. Racionalidade da ação e racionalização social. São Paulo: WMF Martins Fontes, 2011a, v. 1.

HABERMAS, J. Teoria do agir comunicativo. Sobre a crítica da razão funcionalista. São Paulo: WMF Martins Fontes, 2011b, v. 2.

HABERMAS, J. Teoria e práxis: estudos de filosofía social. São Paulo: Editora Unesp, 2011.

HABERMAS, J. La necesidad de revisión de la izquierda. Madrid: Tecnos, 1991.

HABERMAS, J. Três modelos normativos de democracia. Lua Nova, n. 36, p. 39-54, 1995.

HABERMAS, J. Direito e democracia: entre facticidade e validade. Rio de Janeiro: Tempo Brasileiro, 1997.

HABERMAS, J. Mudança estrutural da esfera pública: investigações quanto a uma categoria da sociedade burguesa. Rio de Janeiro: Tempo Brasileiro, 2003.

IIZUKA, E. S.; GONÇALVES-DIAS, S. L. F.; AGUERRE, P. Gestão social e cidadania deliberativa: a experiência de Ilha Comprida - São Paulo. Cadernos EBAPE.BR, v. 9, n. 3, p.748-779, 2011.

IIZUKA, E. S.; GONÇALVES-DIAS, S. L. F.; AGUERRE, P. Reflexões sobre o desenvolvimento territorial sustentável, gestão social e cidadania deliberativa: o caso da bacia do rio Almada (BA). Revista de Administração Pública, v. 46, n. 6, p. 1599-1623, 2012.

NUBE DE PALABRAS. Disponível em: <https://goo.gl/M1vKLP>. Acesso em: 19 jul. 2017.

OLIVEIRA, V. A. R.; CANÇADO, A. C.; PEREIRA, J. R. Gestão social e esfera pública: aproximações teórico-conceituais. Cadernos EBAPE.BR, v. 8, n. 4, p. 613-526, 2010.

OliVeirA, C.; PERAfÁn, M. E.; CONTERATO, M. A. Percepção de atores sociais sobre gestão estratégica e gestão social no âmbito da política de desenvolvimento territorial no Brasil. Desenvolvimento Regional em Debate, v. 3, n. 2, p. 154-175, 2013.

PERES JÚNIOR, M. R.; PEREIRA, J. R.; OLIVEIRA, L. C. Gestão social sob a lente estruturacionista. Revista de Administração Mackenzie, v. 14, n. 6, p. 18-49, 2013.

PERSSON, E. Burocracia, ideologia e gestão social: uma abordagem crítica à luz da categoria habermasiana da esfera pública. $353 \mathrm{f}$. Dissertação (Mestrado em Administração) - Universidade Federal de Santa Catarina, Florianópolis, 2016.

PINHO, J. A. G.; SANTOS, M. E. P. Aporias em torno do conceito de gestão social: dilemas teóricos e políticos. Revista de Gestão USP, v. 22, n. 2, p. 155-172, 2015.

SILVA, T. S.; LIMA, A. A. T. F. C.; GOMIDE, S. C. Inovação na administração pública: um meta estudo dos anais do Enanpad. Capital Científico, v. 15, n. 1, p. 141-159, 2017.

SILVEIRA, D. T.; CÓRDOVA, F. P. A pesquisa científica. In: GERHARDT, T. E.; SILVEIRA, D. T. (Org.). Métodos de pesquisa. Porto Alegre: Ed. UFRGS, 2009. p. 31-42. 
SOUZA, W. J.; OLIVEIRA, M. D. Fundamentos da gestão social na revolução industrial: leitura crítica aos ideais de Robert Owen. Organizações \& Sociedade, v. 13, n. 39, p. 59-76, 2006.

TENÓRIO, F. G. Gestão social: uma perspectiva conceitual. Revista de Administração Pública, v. 32, n. 5, p. 7-23, 1998.

TENÓRIO, F. G. (Re)visitando o conceito de gestão social. Desenvolvimento em Questão, v. 3, n. 5, p. 101-124, 2005.

TENÓRIO, F. G. A trajetória do Programa de Estudos em Gestão Social (Pegs). Revista de Administração Pública, v. 40, n.6, p. 11451162, 2006.

TENÓRIO, F. G. Um espectro ronda o terceiro setor, o espectro do mercado. 3. ed. Ijuí, RS: Unijuí, 2008a.
TENÓRIO, F. G. Tem razão a administração? 3. ed. ljuí, RS: Unijuí, 2008b.

TENÓRIO, F. G. A trajetória do programa de estudos em gestão social (PEGS). In: SILVA JR., J. T. et al. Gestão social: práticas em debate, teorias em construção. Fortaleza: Imprensa Universitária, 2008c. p. 142-159.

TENÓRIO, F. G. Gestão social: uma réplica. In: RIGO, A. S. et al. Gestão social e políticas públicas de desenvolvimento: ações, articulações e agenda. Recife: Univasf, 2010. p. 57-62.

VILLELA, L. E.; PINTO, M. C. S. Governança e gestão social em redes empresariais: análise de três arranjos produtivos locais (APLs) de confecções no Estado do Rio de Janeiro. Revista de Administração Pública, v. 43, n. 5, p. 1067-1089, 2009.

Rafael Junior dos Santos Figueiredo Salgado

ORCID: https://orcid.org/0000-0003-2388-0605

Doutorando em Administração pela Universidade Federal do Rio Grande do Norte (UFRN), Natal - RN, Brasil. E-mail: rafa.salgad@gmail.com

Luana Ferreira dos Santos

ORCID: https://orcid.org/0000-0002-3347-7740

Doutoranda em Administração pela Universidade Federal do Rio Grande do Norte (UFRN), Natal - RN, Brasil. E-mail: luana.f.s.adm@gmail.com

Tamiris Cristhina Resende

ORCID: https://orcid.org/0000-0002-7354-2658

Doutoranda em Administração pela Universidade Federal do Rio Grande do Norte (UFRN), Natal - RN, Brasil. E-mail: tamiriscristhina@gmail.com

Washington José de Souza

ORCID: https://orcid.org/0000-0001-6295-2806

Doutor em Educação pela Universidade Federal do Ceará (UFC); Professor do Departamento de Administração Pública e Gestão Social da Universidade Federal do Rio Grande do Norte (UFRN), Natal - RN, Brasil. E-mail: wsufrn@gmail.com 